\title{
UNDERSTANDING THE BUDAPEST ENTREPRENEURIAL ECOSYSTEM: HUMAN CAPITAL FLOWS AND SOCIAL CAPITAL TIES
}

\author{
Huszák, L., Gittins, T.
}

Loretta Huszák / Institute for the Development of Enterprises, Corvinus University Budapest, Fővám tér 8,1093 Budapest, Hungary. Email: loretta.huszak@uni-corvinus.hu

Tim Gittins / Institute for the Development of Enterprises, Corvinus University Budapest, Fövám tér 8,1093 Budapest, Hungary. Email: tim.gittins@uni-corvinus.hu

\begin{abstract}
Socio-economic transition in the CEE (Central and Eastern Europe) region in recent decades forms the operating context for young entrepreneurial ecosystems. This study has the aim of analysing institutional and cognitive features of CEE ecosystem development by considering Budapest as a prime example of an urban entrepreneurial ecosystem. Alongside the analysis of event registration data, a qualitative research approach is deployed featuring semistructured interviews with entrepreneurs and other institutional actors attending a networking event in Budapest. The methodological foundation for this approach is adapted from Triple Helix ecosystem theory. A conceptual model is produced from the research process, and ecosystem theory is developed by accounting for dynamic human capital flows and social capital ties do not present in the original Triple Helix theory. Results primarily indicate moderate levels of asset values and that attendance by entrepreneurs is largely motivated by locating start-up funding. Prime outcomes of interviews are a lack of innovation-focused specific human capital and increasingly market-based means of social capital development. Furthermore, the findings presented as propositions assume a partial virtual nature for human capital flows and social capital ties between ecosystem actors. On this basis, the resulting conceptual model accounts for the presence of digitalisation. Thus, ongoing entrepreneurial ecosystem development entails continual institutional adaption to information technologydriven socio-economic conditions. The Budapest ecosystem would, however, need to acquire a stronger virtual aspect in order to realise greater growth potential.

Implications for Central European audience: While research on entrepreneurial ecosystems has gained strength, it has barely been applied to the CEE region. This study represents a formative attempt in this regard whereby the resulting conceptual model may be used to empirically evaluate entrepreneurial ecosystems within the region by comparing specific internal and external human and social capital movements. The model primarily implies that digitally derived human and social capital would require deeper integration between start-up firms and institutional actors. Crucially, there is also an implicit need for institutions to develop digitalised infrastructure more intensively in order to nurture innovative start-up activity in the CEE region.
\end{abstract}


Keywords: Entrepreneurial Ecosystems; CEE Region; Innovative Start-ups

JEL Classification: L26, M13

\section{Introduction}

The CEE region faces substantial challenges in terms of entrepreneurial development in a context of socio-economic transition dating from the early 1990s. Early transition featured regulatory and environmental changes to provide favourable opportunities for individuals to start their own businesses (Kornai, 2006). With Hungary widely considered as relatively market-oriented in comparison to neighbouring CEE countries at that time, it has arguably attained a moderate level of entrepreneurial development since. Hence this article focuses on the entrepreneurial ecosystem of Budapest as the main location of economic activity in Hungary.

Extant research on ecosystems in the CEE region remains limited, but there has nonetheless been a focus on entrepreneurial development at the regional level. Szerb et al. (2019) suggest localities are relatively strong in terms of entrepreneurial aspirations, but opportunities to start new businesses are limited by a reluctance to engage in competition. Hence human capital, traditionally defined as the 'sum of skills, knowledge, and capabilities', (Becker, 1964), was characterised as technically oriented in the pre-transition era (Földvári \& van Leeuwen, 2005). Moreover, institutional embeddedness (Welter \& Smallbone, 2011) embodies hierarchical or 'vertically oriented' social capital formation in the CEE region whereby mutually beneficial connections were made between managers of state-run organisations and institutional actors in the pre-transition era. With social capital broadly defined as the creation of business value through formal or informal contact between individuals (i.e., Andrews, 2010; Nahapiet \& Ghoshal,1998), institutional embeddedness is incompatible with globally focused 'horizontally' oriented social capital' featuring contact between actors on a relatively 'equal' basis. The transition has moreover featured substantial entry of multinational enterprises to the region (Békés et al., 2006; Jude \& Silaghi, 2016; Stojčić, 2020). This has led to the existence of 'knowledge spillovers' whereby local enterprises may benefit from innovation-based partnerships with multinational organisations.

The preceding narrative forms the contextual basis for the appraisal of the Budapest entrepreneurial ecosystem. The emergence of information technology (IT) driven globalisation alongside transition in the CEE region has influenced conceptual development of entrepreneurial ecosystems whereby start-up-derived innovation may be facilitated by movement of intangible resources. Innovation in an entrepreneurial context is invariably defined as a means of producing differentiated products and services to provide individual firms with a competitive edge in given sectors (i.e., Aulet, 2013; Ries, 2013). By regarding innovation as the prime driving force of entrepreneurial ecosystems, it entails flows of human capital as a resource stock and the development of social capital ties between individuals, which may take place at networking events as used as the research unit for this study. The research approach is based upon the 'Triple Helix' theory (i.e., Etzkowitz, 2003; Leydesdorff 


\section{DISCUSSION}

\& Deakin, 2011) which provides rationale for resource provision and governance of ecosystems through institutions of government, private business, and higher education.

The rapid global diffusion of new entrepreneurial tools and related methodologies such as the lean entrepreneurship concept (Ries, 2013) has also boosted actual entrepreneurial ecosystem development. This features the development of incubators and accelerators, which are also present in the Budapest entrepreneurial ecosystem. Incubators generally act as means of nurturing early-stage start-ups through the provision of material support such as premises by institutional actors, principally universities. Sansone et al. (2020) developed a taxonomy of 'business' 'mixed' and 'social' incubators to reflect respective entrepreneurial trends. Accelerators represent a more advanced form of start-up nurturing through intensive mentoring of cohort groups (Pauwels et al., 2016). Furthermore, Roundy and Bayer (2019) associate accelerators with increased use of networking events to link start-up entrepreneurs and potential investors, thereby inferring the development of social capital ties which may be located in ecosystems of varying stages of development.

This paper proceeds by initially outlining the theoretical rationale for this study, followed by consideration of Budapest as an entrepreneurial ecosystem. The subsequent section presents the methodological approach initially featuring rationale for descriptive secondary analysis of a sample of participant data at a networking event in Budapest. This is followed by the presentation of reasoning for the qualitative semi-structured interview approach based on grounded research applied to entrepreneurs and other institutional actors in the Budapest entrepreneurial ecosystem. On this basis, the following research questions have been formed:

- What is the main entrepreneurial characteristic of firms attending start-up networking events in the Budapest entrepreneurial ecosystem?

- How does human capital flow between institutions impact upon entrepreneurship in the Budapest entrepreneurial ecosystem?

- How do social capital ties between institutions impact upon entrepreneurship in the Budapest entrepreneurial ecosystem?

The subsequent section outlines the data collection process featuring the use of networking event participant sample data and the semi-structured interview process conducted between May and July 2020. This is followed by a summary of results of secondary data analysis of the sample and of interview findings. This acts as a basis for the development of inductively derived themes drawn from findings in the subsequent discussion section preceding the presentation of the conceptual model. Finally, the research questions are addressed to produce propositions to provide guidance for future research on entrepreneurial ecosystems in the CEE region.

\section{Theoretical Background: Entrepreneurial Ecosystem Development}

Cavallo et al. (2019) indicate the relative infancy of entrepreneurial ecosystem theory in that research activity has only notably accelerated since 2010 . A lack of empirical research and 
conceptual rigor is also widely agreed upon (i.e., Stam, 2015; Acs et al., 2017; Audretsch et al., 2019) to present difficulties in deriving inferences from studies applied in given locations. Most research to this point has been qualitatively oriented and has focused on cities in highly developed economies (i.e., Miller \& Acs, 2017; Walsh, 2019). Spigel and Harrison (2018) also argue that existing research on entrepreneurial ecosystems has not sufficiently explored how they influence the entrepreneurship process.

Innovation and non-innovation drove small and medium-sized enterprises (SMEs) are considered in this study as the prime means of sustaining an entrepreneurial ecosystem. SMEs form a relatively strong proportion of around 67 percent of private-sector employment in comparison with larger enterprises in the European Union (EU), (Eurostat, 2015) ${ }^{1}$, thus illustrating their economic importance. Moreover, empirical studies to this point have insufficiently distinguished between innovative and non-innovative SMEs. It might thus be assumed that the latter form is inclined towards the provision of established products and services, thus assuming a less flexible response to market conditions than innovative counterparts (Ouimet \& Zarutskie, 2014). Carvalho and Yordanova (2018) infer from an EUwide study that 50 percent of SMEs in the EU are non-innovative, which may be attributed to a lack of tangible and intangible resources. Considering SMEs as either innovation or noninnovation-oriented firms, it might be further assumed that for an ecosystem to attain higher development levels through enhanced resource mobility (Brown \& Mawson, 2019), innovation-focused entrepreneurship would need to be actively nurtured by institutional actors in assumed lesser developed locations such as Budapest.

In further relation to innovation-focused SMEs, Blank and Dorf (2012) define a start-up as "a company or a human institution built on different branches, and from which spontaneously arises the condition of extreme uncertainty which has at its core innovation the creation of products and services to revolutionize the market." Blank and Dorf (2012) also suggest any start-up not possessing focus to enable innovation of products or services is unwilling to risk uncertainty and is therefore not a start-up. Essentially, typical motivation for IT start-ups lies in developing drastic innovations that could result in disruptive technology. New entrepreneurs willing to take risks with disruptive ideas may thus create completely new businesses to help stimulate the development of entrepreneurial ecosystems. Due to resource constraints, young start-ups often seek financing for projects to become potentially scalable and profitable. This rationale forms the essence of entrepreneurship as the effective driving force of an entrepreneurial ecosystem.

Triple Helix theory (i.e., Etzkowitz, 2003; Leydesdorff \& Deakin, 2011) assumes interdependence between the three pillars of government, higher education, and private business of the model whereby entrepreneurial behaviour is nurtured to the mutual advantage of all ecosystem actors. The model, however, may not adequately explain why cities such as San Francisco may form advanced ecosystems compared with cities elsewhere (Stam, 2015; Brown \& Mawson, 2019). Moreover, Triple Helix theory does not directly represent entrepreneurship as an outcome of institutional interaction and thus embodies an absence of dynamism necessary for sustained ecosystem development (Cantner et al., 2020).

${ }^{1}$ http://ec.europa.eu/eurostat/statistics-explained/index.php/Statistics on small and medium-sized enterprises (23.08.2021) 


\section{DISCUSSION}

Isenberg (2011) developed an influential entrepreneurial ecosystem model consisting of various intangible elements as opposed to distinct institutional pillars within the Triple Helix model. Hence sustainable entrepreneurship is assumed to lie in specific combinations of such elements in an entrepreneurial ecosystem. The Isenberg (2011) model also cautions against emulating highly developed cases given particular locations may develop ecosystems on the basis of specifically available resources in given localities. Following this theme, Brown and Mawson (2019) developed an ecosystem lifecycle model to propose that globally integrated ecosystems possess a level of start-up experience highly compatible with locally available resource levels. Moreover, the same article suggests that in lesser developed ecosystems, policy tends to be overly focused on start-up development at the expense of developing institutional and governance structures.

The theme of resource flows within entrepreneurial ecosystems is further developed by Spigel and Harrison (2018) to emphasize dynamism between processes and actors, including high-growth start-up firms and established firms. Such established enterprises may not necessarily be SMEs but larger organisations. The extent of connectivity between ecosystem actors in terms of network strength and regularity of process flows between organisations of varying sizes may thus determine the developmental status of ecosystems. Crucially, the Spigel and Harrison (2018) model emphasizes that ecosystems are not necessarily spatially but also virtually based. This is consistent with an emergent theme of digitalisation of technical and cognitive infrastructure of ecosystems. They are thus assumed to acquire a dynamic character whereby they are focused on entrepreneurial opportunity identification and horizontal knowledge diffusion to drive entrepreneurial processes virtually in addition to traditional spatially based factors (Sussan \& Acs, 2017; Autio et al., 2018).

Human capital features strongly in most ecosystem models as an intangible resource. In particular, it plays a central role in Isenberg's (2011) model to encapsulate entrepreneurial mindsets of highly complex individuals as a pre-requisite for entrepreneurial success and ultimately for business growth and development. However, the extent to which human capital may influence the functioning of ecosystems remains relatively under-researched. Hogendoorm et al. (2019), for instance, used a literature review process to suggest that only formal education considered as a human capital antecedent had a marginal effect on entrepreneurial earnings. This aspect supports the rationale for the examination of the nature and extent of human capital flows in the Budapest entrepreneurial ecosystem in this article.

While a lack of managerially oriented human capital in the CEE region is well documented (i.e., Földvári \& van Leeuwen, 2005; Jurajda \& Terrell, 2010; Szerb et al., 2019), its availability is perhaps restricted by skilled labour outflows to Western European countries from new member states ${ }^{2}$ since EU accession began in 2004. A loss of regional human capital (lenciu \& lenciu, 2015; Kovac et al., 2018) may also lead to weak institutional status in terms of ecosystem development in specific locations. Moreover, CEE-based start-up firms may lack innovative potential in terms of impact on the economic performance of regions (Szerb et al.,

\footnotetext{
${ }^{2}$ Estonia, Latvia, Lithuania, Poland, Czechia, Slovakia, Hungary, and Slovenia became EU members in 2004, Romania and Bulgaria in 2007 and Croatia in 2012
} 
2019) which is not perhaps unrelated to an overall lack of managerially oriented human capital. Given the relative newness of entrepreneurial ecosystem theory, extant literature reveals a lack of its application in the CEE region. However, Dvouletý and Orel (2020) conducted an empirical study of 'job creators' in the Czech Republic, Hungary, Poland and Slovakia to suggest that entrepreneurs as employers were more likely to have engaged in higher education than paid employees. While this may reinforce a view of strong human capital levels in the CEE region, it does not provide guidance for consideration of entrepreneurial influence on ecosystem development.

In relation to the impact of social capital ties on ecosystems, Prashantham and Kumar (2011) suggest larger enterprises may utilise horizontally oriented 'bridging' social capital to construct links with locally-based firms to procure resources. As imputed in various studies (i.e. Békés et al., 2006; Jude \& Silaghi, 2016; Stojčić, 2020), larger enterprises may tend to dominate economic activity in the CEE region. Hence asymmetries due to the differing abilities of different sized firms to absorb resources may result in distorted ecosystem development in that larger enterprises may tend to develop links with only specific local startup firms and other established SMEs able to provide resources specific to their needs. Hence typically, larger global enterprises may identify local partners who add value to their activities, but the latter may be encumbered by competitive dependence on a single larger party (Prashantham \& Kumar, 2019).

There is generally an established tradition of studying human capital (Unger et al., 2011) and social capital (Kim \& Aldrich, 2005) as antecedents of individual decisions to become an entrepreneur and thus subsequently contribute to ecosystem development. Personal experience provided by social relationships, exposure to different ideas, mindsets, and beliefs, may also shape a reference framework to support the identification of business opportunities and their development (Davidsson \& Honig, 2003). Growth in the literature on human and social capital in recent decades confirms the relevance of locating and refining related factors for entrepreneurial success.

Budapest has long been generally considered to not only occupy a relatively favourable location within Hungary but also in the CEE region. With Vienna, for example, relatively close, physical infrastructural links between Budapest and other cities in the region present a picture whereby human capital flows and social capital ties may be easily facilitated. While the transition has entailed the creation of a substantial base of SMEs in Hungary, there has surprisingly been scant research on the extent of their innovative orientation. With Budapest as the geographical focus of this study also forming the major centre of economic activity in the country, it is assumed innovative activity mostly takes place within the city. Further assuming innovation is primarily initiated by IT-focused SMEs, official Hungarian statistical data suggests there has been a continuing rise in registrations of IT-focused non-micro-level start-ups in Budapest from 2014-19, as indicated in Table 1: 
Table 1 | Registered IT focused firms in Budapest ${ }^{3}$

\begin{tabular}{cccccccc}
\hline & \multicolumn{7}{c}{ Number of Firms } \\
\hline Number of Employees & Zero & $1-4$ & $5-9$ & $10-19$ & $20-49$ & $50-249$ & Total \\
$\mathbf{2 0 1 4}$ & 6.129 & 10.249 & 530 & 305 & 170 & 73 & 17.456 \\
$\mathbf{2 0 1 5}$ & 5.993 & 10.503 & 526 & 319 & 176 & 73 & 17.590 \\
$\mathbf{2 0 1 6}$ & 7.004 & 9.776 & 520 & 335 & 183 & 91 & 17.909 \\
$\mathbf{2 0 1 7}$ & 6.894 & 10.748 & 524 & 345 & 217 & 101 & 18.829 \\
$\mathbf{2 0 1 8}$ & 6.937 & 11.900 & 541 & 350 & 222 & 103 & 20.053 \\
$\mathbf{2 0 1 9}$ & 4.851 & 15.021 & 529 & 380 & 227 & 119 & 21.127
\end{tabular}

Source: Compiled from publicly available data provided by KSH (Hungarian Central Statistical Office $)^{4}$

Given resource restraints, most start-ups tend to be placed in micro categories of less than ten employees based on EU definitions of SME size by a number of employees (European Commission, 2005) $)^{5}$. Following common definitions of start-up firms being less than five years old (i.e., Ries, 2013; Ouimet \& Zarutskie, 2014). the gradual upward trend over time would suggest a picture of increasing IT-focused start-up activity in Budapest. The data, however, does not account for the presence of longer-established firms in the same given categories. It is also not possible to identify the extent of partnership-based linkage start-up firms may have with multinational firms or to identify innovation-oriented firms within the somewhat broad category of IT services from which data was drawn.

Generally, the growth of registrations of new IT-focused start-up firms would infer a degree of entrepreneurial ecosystem development in Budapest beyond the nascent level. Such growth would also be consistent with relatively strong FDI growth in Hungary over 2009-17 in the years following the global financial crisis of 2008-10 (Engle et al., 2020) and a propensity for IT-focused firms to be 'born-global' in nature in that their market operations are not necessarily restricted to their country of legal registration (Oviatt \& McDougall, 2005). In this regard, new start-up firms may be able to develop social capital ties on both a virtual and actual basis. Moreover, human capital may also be mutually transferred by similar means to enhance entrepreneurial ecosystem development in other locations.

Relatedly, a feature of transition in the CEE region has been a strong extent of foreign direct investment (FDI), principally transferred through the establishment of local subsidiaries of global multinational firms. Inward FDI to the region grew substantially in nominal terms over 2009-176 (Engle et al., 2020) to suggest multinational companies are major providers of

\footnotetext{
${ }^{3}$ Data was collected by use of the EU NACE category JC IT (IT and other information services) and EU NUTS categorisation of Budapest as a specific region.

${ }^{4}$ Data was procured from the KSH link: http://statinfo.ksh.hu/Statinfo/haViewer.jsp (21.08.2021) Please note this data is protected and this link does not lead to the original source. This is acquired by selecting 'registered corporations' and ticking the box 'number of registered corporations' and then selecting 'display'. Data was acquired by selection of 'staff categories' in the left-hand column and use of categories for number of employees as presented in Table 1. Using the same method, NACE category JC IT (information and other services) was also selected as was Budapest as the geographical region.

${ }^{5}$ http://ec.europa.eu/enterprise/policies/sme/files/sme definition/sme user guide en.pdf (23.08.2021)

${ }^{6}$ Data was collected for Hungary, Poland, Romania, Slovakia and Serbia
} 
tangible and intangible resources to influence entrepreneurial ecosystem development at the local level. A resource spill over effect from multinational to local firms in Hungary was identified by Békés et al. (2006). Applied to the CEE region, these factors would infer economic development is based on imported resources. However, Radošević (2017) suggests this has occurred largely at the expense of research-driven innovation. Moreover, Stojčić (2020) points to a tendency for local firms in CEE countries to be deeply embedded in production networks with Western European countries but not in terms of innovation networks. This aspect raises a question in turn of the relative fluidity of social and human capital within the CEE region in terms of the extent to which they might drive ecosystem development in different localities.

While this aspect may suggest the presence of multinational firms in the CEE region may exert a somewhat benign influence on local entrepreneurial ecosystems, the extent to which they influence locally-based innovation patterns is unclear. Bhawe and Zahra (2019) thus notionally suggest stronger heterogeneity of innovative forms in local ecosystems may arise if they were more directly influenced by multinational firms. While there is scant evidence as to the existence of such a phenomenon in the Budapest entrepreneurial ecosystem, examination of locally-based human capital movement and social capital development in this study may help to reveal their nature and extent.

Preceding reference to the overall entrepreneurial environment in the CEE region is integral to focusing on Budapest as the spatial unit of research for this study. It is also on this basis that research gaps have been identified in this section to provide a basis for the development of methodology in this study. In particular, there is a lack of research on human capital flows and social capital ties in relation to entrepreneurial ecosystems in the CEE region. By taking the transitional context of the region into account, this reasoning is specifically applied to Budapest as a prime example of a typical urban ecosystem in the region.

\section{Methodology}

Entrepreneurial ecosystem theory generally attracts criticism in that, given its novelty, some researchers see it as conceptually under-developed with a lack of supporting empirical evidence. For instance, Wurth et al. (2021) propose a transdisciplinary approach featuring consideration of the context and structure of ecosystems in relation to existing theory. With reference to previously identified research gaps entailing a lack of knowledge of human capital flows and social capital ties in entrepreneurial ecosystems in the CEE region, the methodological approach in this study uses Triple Helix theory to provide a theoretical foundation for its application to Budapest. Thus, the institutional pillars of the model act as reference points for the investigation of perspectives on movements of human and social capital within the ecosystem by respective institutional actors. Similarly, this approach is also applied to entrepreneurs themselves.

Application of the Triple Helix model in this regard entails the sensing of novel opportunities involving the creation and absorption of information through scanning the external environment. Diffusion of social capital ties, in particular, assumes a focus on connectedness with actors beyond the boundaries of individual firms to potentially disseminate information, knowledge, and competence in an entrepreneurial ecosystem (Johannessen \& Olsen, 2010). Moreover, in an increasingly digitalised environment, inter-ecosystem cooperation between actors is crucial in terms of creating, selecting, and absorbing information and knowledge. 


\section{DISCUSSION}

This is particularly crucial in terms of identifying appropriate entrepreneurial opportunities, particularly of an innovation-focused nature.

Degrees of collaboration between institutional actors in an entrepreneurial ecosystem might also be assumed to drive the creation and operation of new ventures (Sussan \& Acs, 2017). Hence the methodological approach deployed in this study assumes Triple Helix institutional actors may influence start-up development with the development of new innovative ventures as the prime output. In cognisance of a lack of research on entrepreneurial ecosystems in the CEE region and by following previous research practices applied to entrepreneurial ecosystems in more developed contexts, a qualitative approach is deployed in this study.

The research approach initially proceeds by a sample of participant data drawn from a local networking event. This is then subjected to secondary data analysis on the basis that such events act as prime means of transferring human capital and forming social capital ties. Assuming entrepreneurial intention is strongly associated with youth, Budapest is moreover a prominent student city. Thus, following the rationale developed by Wright et al. (2017) and by Sansone et al. (2021), students typically engage in networking events to seek entrepreneurial opportunities. Moreover, attendance at such events may also be assumed to be associated with the presence of incubator and accelerator-based resources provided by Triple Helix actors.

The main qualitative phase of the research process is based on grounded research theory (Corbin \& Strauss, 2014) to thus examine a hitherto largely under-researched element and thus generate novel insights. This approach is combined with case study-based methodology (Eisenhardt, 1989; Yin, 2017), whereby theory may be further developed through a focused examination of actual entities. This is facilitated by the epistemologically based grounded research approach whereby narrative data drawn from semi-structured interviews is openly codified into themes to inductively derive general findings as to the status of the Budapest entrepreneurial ecosystem. A further stage of inductive thematization involves the identification of narratives common to respondents. Thus, semi-structured interviews were conducted with institutional actors and entrepreneurs to support understanding of the nature of human capital flows and social capital ties in the Budapest entrepreneurial ecosystem.

\section{Data Collection}

Networking event data was initially drawn from the participant database of an event held in April 2020. Such events are regularly organised in Budapest for actors in the entrepreneurial ecosystem, where actual and potential entrepreneurs may meet venture capital investors and other institutional actors. The event chosen for this study is run by a Hungarian company under the licensing contract with a German-based organisation that hosts events in various international locations with the broad aim of enhancing links between start-up entrepreneurs and other institutional actors. The analysed event is held in Budapest annually.

In April 2020, the event was held fully online due to the Covid-19 pandemic and featured 172 presentations with 80 different speakers. The total number of visitors (individuals and enterprises) was 1.615. In our research, we focused on the 112 enterprises and 1.503 individuals attending the event and acting as the population base for the sample of 
representatives of participating enterprises. Participant data were collected using the registration management platform 'talque'. Secondary data analysis was then applied to an overall sample of 112 enterprises represented by participants at the event. This consisted of an examination of the financial records of the sampled enterprises by use of the eBeszamolo ${ }^{7}$ online Hungarian governmental database with 92 percent of the firms legally registered in Hungary. The industrial sectors the sampled enterprises belong to were subject to further categorisation based on The Global Industry Classification Standard (GICS) ${ }^{8}$.

For individual visitors, sample groups were categorised as current and potential entrepreneurs, innovators, and other individuals specifically interested in the longer-term development of Budapest's entrepreneurial ecosystem. Using a key informant approach (Corbin \& Strauss, 2014), a sample of institutional actors and entrepreneurs attending the networking event was approached for an interview. This involved use of a purposive sample technique (Guest et al., 2006) whereby representatives of these desired categories were identified from the talque platform database and approached for an interview. Upon agreement, prospective interviewees provided confirmatory descriptive data of their organisational roles. On this basis, a total of 10 institutional actors as representative of the institutional pillars of the Triple Helix model and 35 entrepreneurs identifying as members of founding teams of enterprises less than five years old agreed to be interviewed, as indicated in table 2 below. Prior to interviews, consent for the recording of transcripts was requested, with interviewees assured of confidentiality. Interviews of approximately a half-hour duration were subsequently conducted online between May 4 and July 17, 2020. The entire process yielded a substantive level of narrative, and with all interviews conducted as planned, it was decided the actual total of 45 interviews exceeded a notional 'saturation point' beyond which further interviews would yield repetitive insights and not be of additional value (Morse et al., 2002).

Table 2 |Semi-structured interview key informants

\section{Institutional Actors}

$\begin{array}{cc}\text { Governmental Institutions } & 3 \\ \text { Higher Education } & 4 \\ \text { Private Business } & 3 \\ \text { Entrepreneurs } & 35\end{array}$

Source: own calculation

Interviews consisted of open questions based on the previously identified research gaps in relation to human and social capital in entrepreneurial ecosystems in the CEE region and were thus designed to elicit a free-ranging narrative. Interviews were recorded and subsequently transcribed word for word by the authors following rationale set out by Corbin and Strauss (2014) and then independently openly codified iteratively until a common narrative emerged. Areas of commonality were categorised as findings. Verification of

\footnotetext{
${ }^{7}$ https://e-beszamolo.im.gov.hu/oldal/kezdolap (21.08.2021) Companies or associations registered in Hungary must file a company tax return annually by May 31st. In 2020, this deadline was extended due to the Covid-19 pandemic to the end of September.

${ }^{8}$ The GICS structure consists of 11 sectors, 24 industry groups, 69 industries and 158 sub-industries. This classification system has been widely accepted as an industry analysis framework.
} 


\section{DISCUSSION}

narrative was subsequently achieved to result in consolidation of coded themes and thus ensure validity and reliability of findings (Morse et al., 2002, Guest et al., 2006).

\section{Research results}

With an initial focus on secondary data analysis, most sampled organisations attending the networking event were identified as IT companies which included the provision of software and related services, technology hardware, and equipment (Figure 1). Companies included in this category provide services for the IT industry, such as data processing and outsourcing. The category also includes companies providing web hosting, IT consulting, and information management services.

The second main sector where most participating Hungarian start-ups and larger enterprises are categorised is defined as 'Industrial'. This category includes companies providing business support services, employment agencies, employee training, payroll \& benefit support services, retirement support services, and other types of agency-based service. Transportation, logistics, and manufacturing companies also belong to this category. In overall terms, results indicate a strong representation of service-focused organisations. This, in turn, presents a picture of increased focus on IT orientation in the Budapest entrepreneurial ecosystem.

Figure 1 | Sectoral categorisation of participating enterprises at the networking event

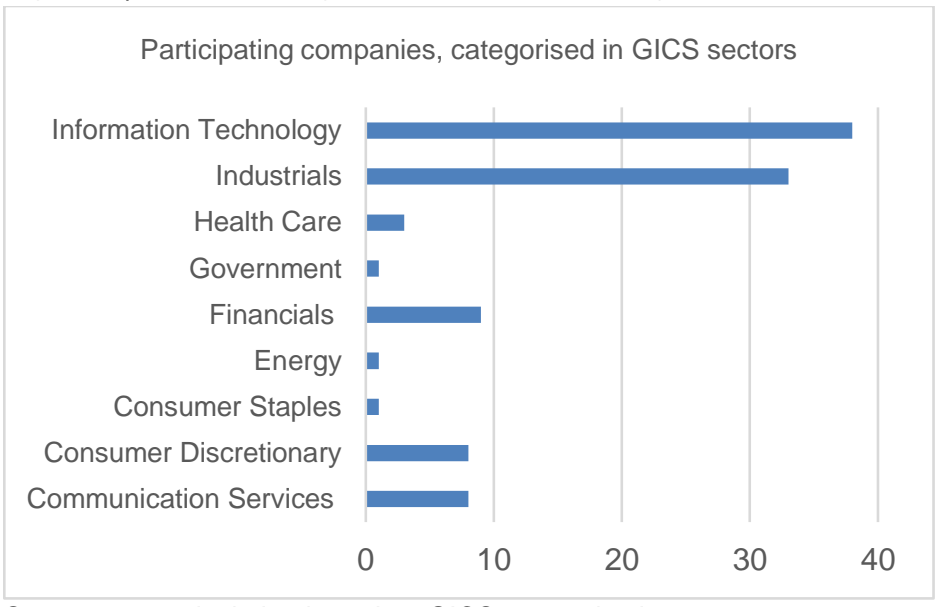

Source: own calculation based on GICS categorisation

Given the EU definition of SMEs at less than 250 employees, figure 2 indicates a strong presence of small enterprises at the event. However, findings indicate that not only start-ups or new ventures are interested in attendance but also larger, more mature enterprises, albeit to a far lesser extent. 
Figure 2 | Size of participating enterprises at the networking event

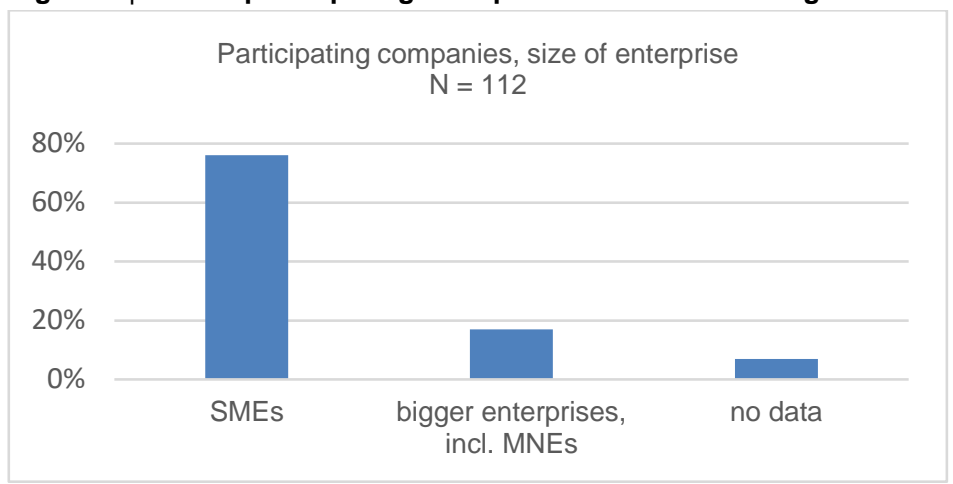

Source: own calculation

Findings illustrated in Figure 3 indicate that only a few SMEs participating at the event possessed asset values higher than 1 billion Hungarian forints (approximately 2,81 million EUR at June 2021 exchange rates), which is well below the EUR 43 million net asset threshold. EU definitions of SMEs also include reference to financial statements, principally balance sheets and income statements. Enterprises may choose between annual turnover not exceeding EUR 50 million or the annual balance sheet net asset value not exceeding EUR 43 million to be accepted as a small or medium-sized company. ${ }^{9}$ Therefore, most networking event participants belong to the category of micro-enterprises, with fewer than ten employees and with an annual balance sheet asset value lower than EUR 2 million. This would suggest a tendency towards micro-sized enterprises in the Budapest entrepreneurial ecosystem, as noted in figure 1. Financial constraints faced by firms in this category would also suggest attendance at the event is primarily motivated by seeking financial support for developing potentially innovative products and services.

\footnotetext{
${ }^{9}$ The category of micro, small and medium-sized enterprises consists of enterprises employing less than 250 persons with either annual turnover not exceeding EUR 50 million or an annual balance sheet total not exceeding EUR 43 million. Commission Recommendation 2003/361/EC, as published in the Official Journal of the European Union L 124, p. 36 of 20 May 2003 forms the authentic basis for determining conditions regarding qualification as an SME.
} 
Figure 3 | Assets of enterprises participating at networking event

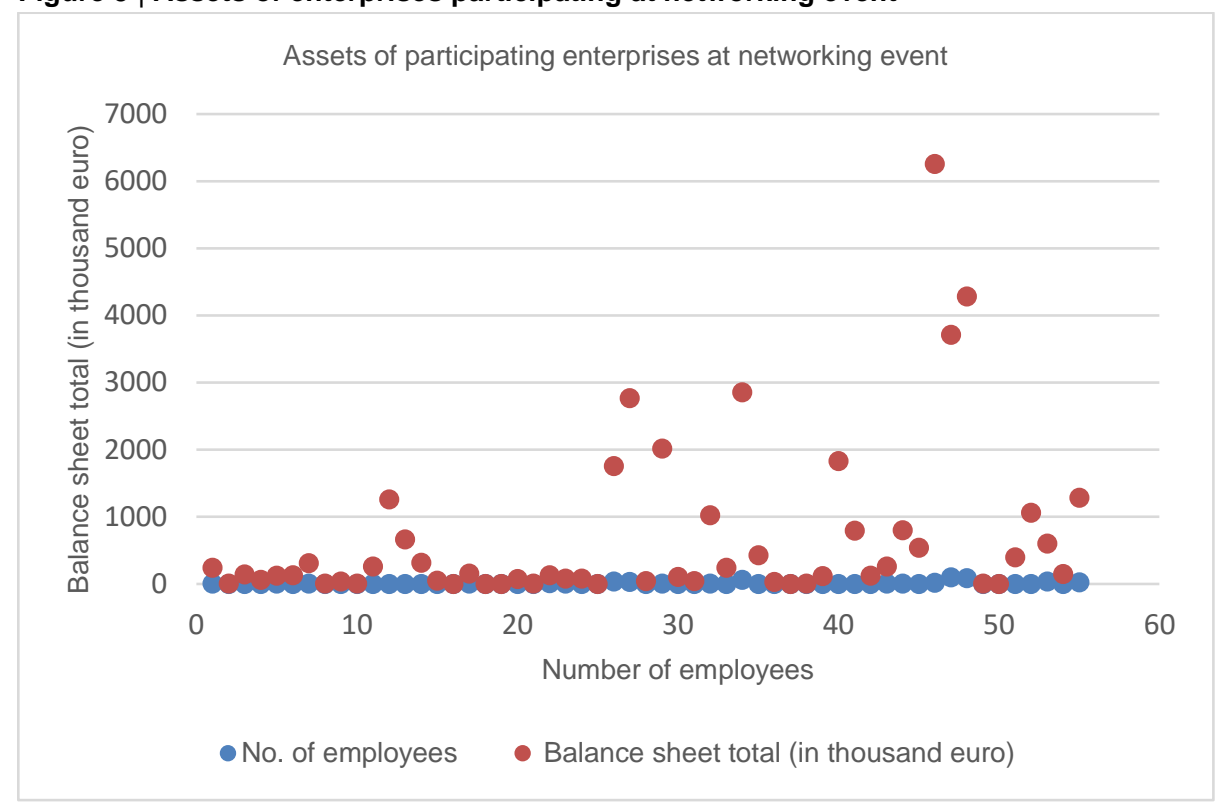

Source: own calculation based on the eBeszamolo online database.

The following semi-structured interview finding category titles represent open codes as outlined in the data collection section whereby examination of narrative drawn from interview respondents has resulted in areas of commonality. Respondents are denoted by the following prefixes: G - governmental institutions; H - higher education; B - Private business; E Entrepreneurs.

a. Governmental policy focuses on potentially highly innovative start-up firms.

Three interviews were conducted with representatives of the Ministry of Innovation and Technology (G1), a predominantly government-funded venture capital (VC) provider (G2), and the Hungarian Intellectual Property Office (G3). G2 suggested 'the state has an important role in the venture capital industry in Hungary but VC investments can offer a suitable supply of capital for the development of young, innovative firms'. Moreover, G1 stated a prominent presence of state-owned and hybrid (private-public) venture capital providers at the networking event is 'significant but not surprising'. This would further corroborate a picture of imbalanced entrepreneurial ecosystem development in Budapest in terms of the private venture capital market not being able to absorb an increased supply of capital without the support of state-owned VC firms.

b. Nurturing of start-ups is prioritised besides financial support. 
E15 stated that 'technology start-ups do not receive any targeted tax incentives in Hungary' but 'must bear the same financial burden as larger companies' ${ }^{10}$. However, according to Gl and G3, the government's research and development (R \& D strategy) also include objectives for building a 'start-up ecosystem'. In recent years, significant state-own resources have been allocated to improve the incubation of domestic start-ups. G3 explained the existence of a funding program is known as "Start-up Factory" with a total budget of around 5.75 million EUR and up to approximately 862,000 EUR of funding per incubator and is coordinated by the National Research, Development, and Innovation Office, with the policy support of the Ministry for Innovation and Technology ${ }^{11}$.

Several entrepreneurs attending the networking event suggested Budapest possesses typical elements of start-up nurturing infrastructure with the networking event attended by representatives of prominent local incubators and accelerators. While the total number of incubators and accelerators in Budapest is unknown, based on interview comments from entrepreneurs, it is not expected to be large. E8 suggested that 'Incubators and accelerators focus more on providing office space than on professional support'. E27 further stated that through the networking event, 'a lot of attention was paid to education' through the provision of training in intellectual property awareness and management in general.

\section{c. Strong dependence of start-ups on state-based institutional support.}

Several entrepreneurs (i.e., E7, E11, E24) suggested limited access for early-stage start-ups to private-sector financial funding sources. This further corroborates a picture of underdeveloped private sector venture capital activity in the CEE region, as depicted by Karsai (2018). Furthermore, E29 and E31 felt venture capital requirements to be overly stringent and thus leading to greater dependence for support on state-based institutions.

\section{d. A lack of institutional knowledge and awareness of core business activities of start-ups.}

E2 and E8 noted improvement in terms of accessing state-based institutional support as for example, in the promotion of networking events. However, both interviewees felt governmental institutions have limited awareness of networking activities, particularly at the international level. This would infer the development of social capital ties to be primarily concentrated locally within the spatial parameters of the Budapest entrepreneurial ecosystem.

\section{e. Entrepreneurial knowledge is mainly developed through class-based activities in universities.}

There are 30 registered higher education institutions in Budapest ${ }^{12}$, of which of those offering business-related courses, only two are in the private sector. In terms of delivering entrepreneurship programs, $\mathrm{H} 2$ cited a 'lack of financial support for extra-curricular activities', principally through incubator provision, which is practiced by at least three universities. H4 suggested 'pedagogy is still mainly class-based' thereby inferring insufficient emphasis on the acquisition of actual entrepreneurial experience.

\footnotetext{
${ }^{10}$ Since there is no general agreement as to the point when a startup firm becomes mature, a five-year cut off point is assumed for the purpose of this study.

${ }_{11}$ https://nkfih.gov.hu/palyazoknak/nkfi-alap/startup-factory-2020-114-startup/palyazati-felhivas (21.05.2021)

12 https://www.unipage.net/en/universities/budapest (21.08.2021)
} 


\section{DISCUSSION}

\section{f. Universities are developing links with organisers of networking events.}

The importance of enhancing the wider social role of universities through their presence at networking events was cited by all four higher education interviewees. $\mathrm{H} 1$ specifically mentioned that this might entail extra-curricular knowledge dissemination, but in overall terms, interviewees offered no clear picture of the extent and nature of effectiveness of such activities as applied to networking events.

\section{g. Universities are insufficiently involved in entrepreneurial ecosystem development.}

Several interviewed entrepreneurs suggested means of university support for start-up enterprises could be diversified in terms of extra-curricular activities. For example, E18 felt 'it would be great if Hungarian universities took part more actively in the ecosystem'. However, E3 suggested 'university participation in networking events is only superficial'. Other interviewed entrepreneurs (i.e., E9, E25, E31) all cited a major reason for them attending networking events with university participation as a means of developing 'networking ties', thereby locating students as suitably talented employees or potential partners. Universities were not generally seen by interviewed entrepreneurs as explicitly fostering the development of social capital ties but rather as disseminating their own capabilities through participation in networking events.

h. A relatively small but growing venture capital sector exists within the Budapest entrepreneurial ecosystem.

The three 'private business' interviewees (B1, B2, B3) were all venture capital providers. All three cited a strong preference to share information on prospective investment start-up targets with other interested parties within the local entrepreneurial ecosystem. B2 suggested a nascent presence of 'business angels' as high net worth individuals seeking start-ups for investment (Tenca et al., 2018) and that such individuals are well acquainted with governmental funding activities. A definitive number of venture capitalists and business angels in Budapest could not be determined, but B2 and B3 agreed it was likely to be relatively low in comparison with locations such as Berlin.

i. Relatively few start-ups are provided with private venture capital funding, but its extent may be increasing.

Several interviewed entrepreneurs (i.e., E13, E19, E23, E26) suggested investors used an increasing number of networking events as a prime means of gathering information on potential investment targets. E23 mentioned that 'events present opportunities for an informal presentation of ideas' for assessing investment potential. This in turn, would suggest reinforcement of a picture of intimate social capital ties between investors consistent with nascent entrepreneurial ecosystem development. Moreover, E19 and E26 suggested entrepreneurs are increasingly interested in online 'crowdfunding' as a capital-raising technique.

j. $\quad$ Networking events are the prime means of attracting the attention of investors. 
E4 and E32 cited a limited number of private investors attending networking events to infer intense competition from entrepreneurs for their attention. Furthermore, E14 suggested attendance of networking events presented a strong element of 'chance' in meeting a relatively small circle of potential investors. Given Budapest is a medium-sized capital city with an overall estimated population of 1.7 million in $2021^{13}$, the exchange of social capital ties can also thus be assumed to be relatively intimate.

\section{k. Start-ups lack clear goals in terms of expectations from investors.}

Several entrepreneurs (i.e., E15, E22, E25) suggested networking events were an ideal form of 'meeting new contacts'. E2 felt most start-up entrepreneurs tended to attend such events with 'poorly formed business plans to present to potential investors and partners'. This in turn, would raise the question of expectations of attendance at such events, which may be more generally focused on social capital tie construction rather than forming specific relationships.

\section{A lack of industry-specific skills exists on the part of potential employees.}

Most interviewed entrepreneurs generally agreed on a strong level of potentially talented employees graduating from local universities. However, E16 and E27 expressed difficulty in terms of procuring staff with skills in line with their specific business needs. Relatedly, E4 and E 21 felt that institutions devoted insufficient investment to human capital development in terms of addressing digitalisation trends.

\section{m. Presence of a tendency towards online recruitment.}

E13 and E28 agreed that online recruitment was more effective in terms of locating talented individuals to meet their own business needs. Moreover, several interviewed entrepreneurs (i.e., E6, E13, E29, E33) felt that offline networking events were relatively ineffective for such purposes. E11 suggested talented employees may also be recruited online from outside the spatial remit of the Budapest entrepreneurial ecosystem, thus implying the existence of virtuality in terms of entrepreneurial ecosystem development.

\section{n. Training and development activities tend to be conducted by start-ups themselves.}

Perhaps in relation to a lack of institutional investment in human capital noted in finding I, several interviewed entrepreneurs (i.e., E8, E20, E29) agreed on a tendency for start-ups to practice 'in house' training activities in both technical and 'soft' skill areas. E20 suggested soft skill training entails the development of communicational, sales, and marketing skills to complement technical skills to develop multi-skilled employees.

\section{o. Direct personal contact was preferred to the attendance of networking events.}

Several interviewed entrepreneurs (i.e., E5, E17, E22, E28) felt that business relationships were more likely to develop through the utilisation of personal ties rather than attending networking events. This is also reflective of the intimate nature of the Budapest start-up community, where according to E5 'many people are known to each other'. Furthermore, E22 felt online forms of contact as similarly effective as traditional offline forms.

${ }^{13}$ https://worldpopulationreview.com/world-cities/budapest-population (21.08.2021) 


\section{DISCUSSION}

p. Networking events may be more effective for older start-ups than for younger firms.

E12 and E34 suggested personnel of younger firms may feel a more urgent need to attempt to access potential investors at networking events. E23 moreover suggested older counterparts may have developed ties with investors to a deeper degree and thus may see the value of networking events to be of lesser importance.

\section{q. There is a lack of internationally focused networking events in Budapest.}

Regardless of online or offline delivery form, E7 and E18 felt local networking events were generally felt too 'large' for start-up entrepreneurs to potentially develop deep social capital ties. However, E26 felt that the Covid-19 pandemic would result in more networking events being held online and therefore assuming a stronger international dimension.

\section{Discussion}

Research gaps at the end of section one indicate a deficiency of studies on human capital flows and social capital ties in CEE-based entrepreneurial ecosystems. This section, therefore, attempts to synthesise research findings to provide an overall view of these forces within the Budapest entrepreneurial ecosystem.

Firstly, descriptive secondary data analysis infers participation in the networking event by entrepreneurs is primarily motivated by prospects of locating funding sources. Most participants have identified as representative of IT sector companies with relatively low asset values, as indicated in figure 3. It might therefore be deduced that attendance at such events is dominated by representatives of IT-focused start-ups seeking to enhance intangible resource levels in the form of human capital and to initiate and deepen social capital ties with institutional actors.

In relation to the view that multinational organisations in the CEE region may perhaps benignly influence local innovation patterns (i.e., Békés et al., 2006; Stojčić, 2020), the presence of representatives of larger enterprises at the event is interesting. Interview findings suggest they may use such opportunities to identify local entrepreneurs to form viable partnerships with or to locate talented individuals for employment. However, no overwhelmingly definitive evidence emerged to this effect from this study to thereby pose a question of further research in this regard.

By following previously outlined open coding rationale (Corbin \& Strauss, 2014), the codified semi-structured interview findings were further subjected to textual analysis to inductively derive four prominent themes as follows:

\section{a. Policy support measures tend to focus on start-up entrepreneurial activity.}

The emergence of this theme is consistent with observations made by Brown and Mawson (2019) and by Stam (2015) in that lesser developed ecosystems tend to feature strong policy focus on start-up companies at the expense of the entire SME sector as a whole. Findings a and $b$ would moreover suggest a strong degree of governmental involvement within the Budapest entrepreneurial ecosystem, as in, for example, support for incubator and 
accelerator development. Putative evidence of upward trends of registration of IT sector SMEs (Table 1) and attendance of IT sector entrepreneurs at networking events would moreover suggest nascent development of entrepreneurial culture.

However, in relation to transition in the CEE region, institutional ecosystem governance might however still be largely cognitively based in terms of emphasis on potentially high growth start-ups as a prime means of attaining economic status enjoyed by more advanced economies. This may be misguided in that such a perspective may not extend to the entire SME base within the Budapest entrepreneurial ecosystem regardless of the innovation orientation of firms. Neither may it adequately account for the development of 'digital infrastructure' enhancing the evolution of actual/virtual ecosystems (Autio et al., 2018). This aspect is moreover imputed in findings $\mathrm{m}$ and $\mathrm{q}$ relating to tendencies towards online networking. This has implications in terms of the nature of social capital ties which are thus assumed to acquire a greater degree of 'horizontal' or egalitarian orientation (Andrews, 2010) with enhanced digital contact between ecosystem actors.

\section{b. State-based domination of investment provision.}

This theme emerged primarily from findings $b$ and $h$, thus inferring the existence of a relatively small but growing private venture capital sector in Budapest. This would also corroborate a picture of the major share of venture capital investment in the CEE region executed through the national government and EU funding (Precup, 2017; Karsai, 2018). Moreover, an 'Invest Europe' report (2019) suggests private equity investment activity in Hungary in 2018 accounted for 13 percent of the total in the CEE region compared with 32 percent in Poland and 29 percent in the Czech Republic. This would suggest that, by comparison, Hungary possesses a relatively smaller private investment industry. It would also represent linkage with the previous theme in that a strong focus on state-driven funding of entrepreneurship would, by implication, embody inconsistency with the development of market-driven entrepreneurial culture. Kállay and Jáki (2019) corroborate this view by indicating that although the Hungarian state allocated significant resources to funding VC investments from 2010 , the value of average yearly investment barely grew. However, the same study indicates the share of public resources placed on the funding market increased from $4 \%$ to $86 \%$ in Hungary between 2010 and 2018.

Finding $\mathrm{h}$ suggests prominent roles appear to be played by specific individuals who may be characterised as 'business angels' with intimate knowledge of particular high potential ventures and state-based funding opportunities. This may also represent a tendency for innovative enterprises to seek government-based funding in the CEE region (Belas et al., 2017). Based on findings $h$ and $j$ this is corroborated by a presumed relatively small size of the private venture capital sector in Budapest. Furthermore, dependence on governmentbased funding may also be related to the transitional status of the CEE region. In this regard, the Budapest entrepreneurial ecosystem may not have fully acquired cultural norms whereby private venture capital may be provided on a wider and deeper scale.

While finding e provides evidence of facilitation of incubators by universities, there would appear to be an overall low presence of accelerators. This would again infer a nascent level of human capital provision from institutional actors to start-up entrepreneurs. Furthermore, the use of online crowdfunding as an effective and innovative means of raising finance, as indicated in finding $\mathrm{i}$ is acquiring greater use in the CEE region despite a perceived relatively 


\section{DISCUSSION}

small consumer base (Zetzsche \& Preiner, 2018). This would suggest alternative funding methods might with time, serve to redress overdependence on state-derived funding in the longer term.

\section{c. Entrepreneurial ecosystem development is hindered by outmoded means of human capital formation.}

Findings e, $f$ and $g$ reinforce outcomes of a multi-country European study (Küttim et al., 2014), suggesting that universities considered as human capital providers engage mostly in classbased entrepreneurial education. In relation to the CEE region, findings in this study also support a picture of the overall public under-investment in higher education under transition (Brajkovic, 2018). The same findings also infer entrepreneurship education provision in Budapest may not be adequately matched with current economic traits, including those of digitalisation. The prevailing emphasis in the CEE region on traditional development of technically related human capital, as noted for example, by Földvári and van Leeuwen (2005) and by Jurajda and Terrell (2010), might also be derived from findings I and $\mathrm{n}$. This is consistent with perspectives on substantial drainage of human capital from the CEE region to Western Europe since EU accession (Ienciu \& lenciu, 2015; Petersen \& Puliga, 2017) to infer that a limited pool of talented employees remains in the CEE region. Hence competitiveness levels of locally-based talented individuals may rise in terms of locally-based employment. Moreover, based on a study of CEE-based universities, entrepreneurial inclinations of higher education students in Hungary appear to be increasing (Gubik \& Farkas, 2016).

In overall terms, a picture is derived of human capital as insufficiently developed in terms of non-technical or managerially oriented skills. Findings I and $\mathrm{n}$, in particular, pointed to a lack of industry-specific and entrepreneurial skills within the pool of available university graduates and that training and development activities largely take place within enterprises. This aspect also suggests linkage with the theme a in that generic training and higher education programs may be ineffective in terms of meeting specific needs of firms within the Budapest entrepreneurial ecosystem. Of further note in this regard is a tendency towards online recruitment, which would infer an element of doubt on the notion of ecosystems as singly discrete spatial entities if talented employees can be recruited from different physical locations and work remotely.

\section{d. Social capital networks increasingly assume stronger horizontal and virtual characteristics.}

An implicit preference towards fostering of deep social capital ties between entrepreneurs and institutional actors was noted in findings $o$ and $p$. Preference for direct contact between representatives of start-ups and institutional actors as inferred from finding o would infer affinity with vertically oriented social capital tie development. This is perhaps primarily due to the relatively early stage of development of the Budapest entrepreneurial ecosystem, which is characterized by strong governmental involvement at an institutional level. Moreover, this aspect would infer that the predominance of vertically oriented social capital ties inherited from the pre-transition period in the form of institutional embeddedness (Welter \& Smallbone, 2011) may still prevail. 
Although the presence of representatives of larger enterprises at the networking event was not specifically elucidated in interview findings, this aspect may present further competition for limited human resources in CEE contextual conditions (Petersen \& Puliga, 2017). A picture of a lack of innovative capacity in the CEE region, alluded to by Radošević (2017) and by Stojcic (2020), is also reinforced through finding I highlighting a lack of talented employees within the Budapest entrepreneurial ecosystem. This aspect may, in turn, be addressed by the fostering of virtual social capital ties with actors in other spatial entrepreneurial ecosystems. Moreover, the use of horizontally oriented 'bridging' social capital ties (Andrews, 2010) whereby links are made by virtual means with contacts outside the spatial boundaries of the entrepreneurial ecosystem (i.e., Sussan \& Acs, 2017; Autio et al., 2018) might be taking place. Although evidence from findings of this study for such a phenomenon in social capital terms is limited, a tendency for online recruitment of human resources as drawn from finding $\mathrm{m}$ would suggest it may be active.

With the event held online in early 2020 due to the Covid-19 pandemic, the nature of social capital tie formation directly assumed an entirely virtual dimension. This would suggest a serendipitous shift towards virtual entrepreneurial ecosystem development in that attendance possibilities were widened by such means without regard to geography. Attendance by startup entrepreneurs at the networking event appears to conform to aspects of horizontally oriented social capital in that potential partners and employees may be sought on a relatively egalitarian basis as inferred from findings $\mathrm{j}$ and $\mathrm{m}$.

Findings $\mathrm{b}, \mathrm{j}, \mathrm{k}$ and $\mathrm{m}$ would also putatively suggest the evolution of a hybrid actual/virtual ecosystem in which digital technologies enabling virtual contact can be viewed as 'non-living components', and human networking event participants using virtual technology are viewed as 'living components' (Sussan \& Acs, 2017). This aspect would also provide a partial rationale for the formative development of Budapest as an actual/virtual entrepreneurial ecosystem. This reasoning is based on the formation of social capital ties between the living and non-living components that result in dynamic and continuous change.

The preceding rationale outlined in the preceding themes forms the basis for the development of an entrepreneurial ecosystem model adapted from the original Triple Helix theory as outlined in Figure 4. 
Figure 4 | Budapest Entrepreneurial Ecosystem: Human capital flows and social capital ties

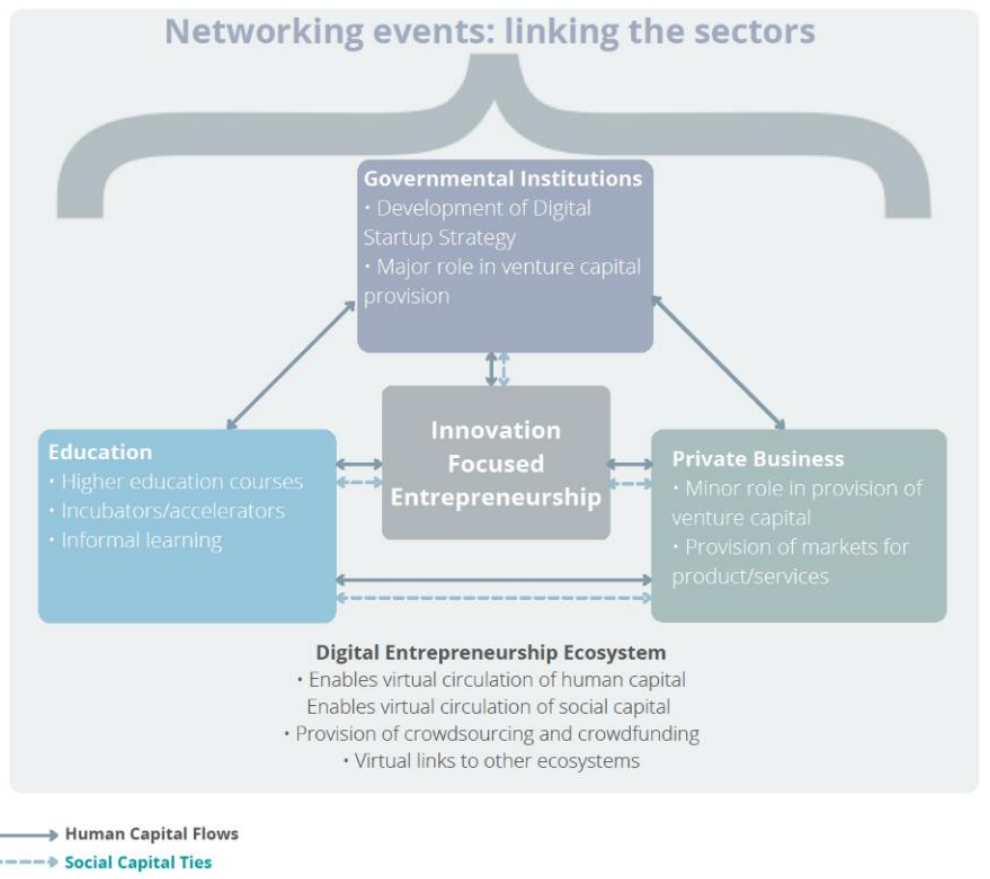

Source: own illustration based on work by Etzkowitz (2003) and Leydesdorff and Deakin (2011)

The conceptual basis for the revised model is derived from the three institutional pillars of Triple Helix theory (i.e., Etzkowitz, 2003; Leydesdorff \& Deakin, 2011) in the form of higher education, private business, and governmental institutions. On the basis of analysis in this study, Triple Helix theory acquires a dynamic element whereby human capital flows are assumed to be mutually exclusively transmitted between the ecosystem pillars by traditional and virtual means. Social capital ties between individuals in start-up ecosystems are also assumed to be initiated and developed by such means. Human capital is thus assumed to flow between pillars in the form of transfer of skills, knowledge, and capabilities of entrepreneurial ecosystem participants. However, social capital ties between ecosystem actors are assumed to be developed at actual/virtual networking events and through other means of actual/virtual contact.

Principally, digitalisation is assumed to act as a virtual mechanism for the transmission of human capital and the development of social capital ties within the ecosystem. The conceptual basis for digitalisation is moreover drawn from the rationale for both digital and spatial factors driving structural ecosystem development processes (Sussan \& Acs, 2017; Autio et al., 2018). The model moreover assumes that digitalisation embodies the institutional pillars of Triple Helix rationale in a partially virtual context. 
Innovation-focused entrepreneurship is placed as an interdependent entity in the model following rationale set out by Ries (2013) and Ouimet and Zarutskie (2014), in that it is assumed to be the dynamic focus of institutional means to develop the entrepreneurial ecosystem and thereby attain higher levels of development. Moreover, virtual/actual circulation of human capital and development of social capital ties is assumed to lead to the attainment of such levels of ecosystem development than solely under non-digitalised conditions. In overall terms, the themes derived in this paper suggest Budapest is located at a somewhat lower developmental level than might be identified in entrepreneurial ecosystems located in more developed and proximate economies such as Vienna. On such a basis, the comparative extent of innovation-focused entrepreneurship in Budapest is assumed to be moderate.

The extent and nature of entrepreneurial ecosystem development in Budapest is accounted for by the incorporation of the themes of this paper into the institutional pillars of the Triple Helix model. Principally, the strong role of government as a venture capital provider and regulatory authority is representative of lower levels of ecosystem development compared with relatively developed ecosystems. Moreover, the strong presence of multinational companies in Hungary (Békés et al., 2006; Szerb et al., 2019) also provides a substantial client base for products/services offered by innovation-focused start-up enterprises based in Budapest. Social capital ties between actors in governmental and higher education institutions are assumed to be somewhat dormant in that interview findings provide little evidence to this effect, although according to interviewee G3 the Hungarian Intellectual Property Office is active in this regard.

The presence of digitalisation may also be manifested in non-traditional financing forms such as crowdsourcing and crowdfunding, which in turn may drive a more digitally focused complexion of governmental support. In the current Covid-19 context, digitalisation provides means for virtual hosting of networking events and potentially linking ecosystem actors based in other geographical locations. Thus, it is proposed the Budapest entrepreneurial ecosystem is not merely grounded in spatial terms to therefore present a virtual/actual manifestation of its functioning. Given Budapest's relatively central location in the CEE region, the ecosystem may converge in the long term with those of relatively close neighbouring ecosystems to form a regional ecosystem, as suggested in the case of Vienna by Radinger-Peer et al. (2018).

Ultimately the model presented in figure 4 demonstrates human capital flows and social capital ties to be multi-directional between institutions and entrepreneurs on both an actual and virtual basis. Triple Helix theory is therefore adapted to assume an actual/virtual nature that is dynamic in terms of focus on entrepreneurship as the means to attaining higher levels of entrepreneurial ecosystem development.

\section{Conclusion}

Considered within the growing corpus of literature on entrepreneurial ecosystems, this study represents a formative attempt to evaluate the nature of an entrepreneurial ecosystem in a city in the CEE region. Primarily, the presence of a nascent innovation-focused start-up sector is noticeable in Budapest, with an ongoing movement towards the formation of horizontal social capital ties. The supply of suitably talented human capital to nurture further entrepreneurial ecosystem development may, however, be restricted. In consistency with observations on developing ecosystems in recent scholarly contributions (i.e., Goswami et 


\section{DISCUSSION}

al., 2018; Brown \& Mawson, 2019), thematic evidence suggests that institutional support is somewhat mismatched with current macro-economic trends towards digitalisation. In overall terms, a picture of a complex and dynamic entrepreneurial ecosystem has emerged. The extent to which the research questions posed in the introduction have been addressed are summarised to produce propositions as follows:

RQ1: What is the main entrepreneurial characteristic of firms attending networking events?

Thematic analysis derived from themes $a$ and $b$ in the preceding section suggests attendance at the networking event by start-up entrepreneurs is primarily motivated by the needs to develop social capital ties with institutional actors. Hence it is assumed the prime entrepreneurial characteristic of firms attending the event is that of a lack of internal capabilities to enable them to develop products and services as independently as they otherwise might. This is also indicated by the relatively low level of asset values of participating firms drawn from secondary data analysis from which the first proposition P1 is derived:

P1: Low resource levels in the Budapest entrepreneurial ecosystem reflect low levels of entrepreneurial ecosystem development in the CEE region.

RQ2: How does human capital flow between institutions impact upon entrepreneurship in the Budapest entrepreneurial ecosystem?

An overall picture of a limited supply of human capital is presented in theme c, which, however, may differ in terms of its general transferability between occupational sectors as opposed to a specific focus on given skill areas (Becker, 1964). Domination of technically focused human capital in the Budapest ecosystem may infer orientation towards specific human capital usage in this regard. Findings $\mathrm{I}, \mathrm{m}$ and $\mathrm{n}$ moreover suggest a lack of specific human capital in relation to innovation-focused sectors. A preference for general training and development by start-up entrepreneurs would, in turn, suggest the shifting of focus towards that of general human capital development consistent with digitalisation trends. Thus, the changing nature of human capital flows may be instigated by entrepreneurs themselves within the ecosystem. This is assumed to be primarily influenced by the presence of digitalisation in the preceding model, whereby human capital is partially absorbed from other spatial ecosystems. This leads to the second proposition P2:

P2: Digitalisation increasingly influences the extent and nature of human capital flows within the Budapest entrepreneurial ecosystem.

RQ3: How do social capital ties between institutions impact upon entrepreneurship in the Budapest entrepreneurial ecosystem?

The presence of digitalisation in the conceptual model would suggest a shift towards the use of horizontally oriented social capital ties to enable the formation of deeper relationships between ecosystem actors. Evidence in this study would suggest such a shift is not clearly discernible, however, it might be argued that it may be significantly facilitated through digitalisation as imputed in theme d. Moreover, in the current Covid-19 context, it might be further argued that horizontal social capital formation is increasingly facilitated by virtual means. This aspect may not only apply to entrepreneurs but other institutional actors in terms 
of a gradual cultural shift whereby social capital ties are increasingly formed on both a more egalitarian and virtual basis leading to the third and final proposition P3:

P3: Social capital formation in the Budapest entrepreneurial ecosystem is acquiring a stronger virtual dimension to proceed to higher levels of ecosystem development.

\section{Limitations}

As with all studies of this form, this article is not without limitations. Firstly, the sample of networking event participants was collected from data drawn from a single event which is not representative of the entire innovation-focused start-up sector in Budapest. With a limited sample base, only descriptive analysis is feasible, and any imputations for how the data may impact upon the functioning of the entrepreneurial ecosystem are also limited. Secondly, motivation for attendance by representatives of start-up enterprises would require a far more focused empirical research approach. Categorisation of participating firms as SMEs and larger organisations is also somewhat broad. Thirdly, results did not reveal a clearly identifiable pattern of the relative strength levels of innovative and non-innovative SMEs in the Budapest entrepreneurial ecosystem.

By using the Triple Helix theory as a means of appraising a relatively under-developed entrepreneurial ecosystem, this study has demonstrated an element of dynamism through human capital flows and social capital ties. Thus, future studies may consider innovationfocused entrepreneurship acting as a recipient mechanism for such dynamic forces partially transmitted by institutional actors. Hence innovation-focused entrepreneurship may act as a dependent variable, with institutional pillars acting as independent variables. The extent and nature of innovation-focused entrepreneurial activity as output may thus be moderated or mediated by human capital flows and social capital ties.

Given the CEE transitional context for this study, in policy-related terms, the resulting model may be used as a template for comparison of the relative effectiveness of institutions upon urban entrepreneurial ecosystems in the region. It may also assist in the evaluation of entrepreneurial ecosystem effectiveness as such by moving beyond descriptive methods of measuring entrepreneurial activity to incorporating qualitative perspectives on human and social capital within ecosystems. Theory and policy development would also need to account for digitalisation by considering its effect on entrepreneurial ecosystem development through human and social capital transmission.

In overall terms, this study represents an initial attempt to appraise the entire Budapest entrepreneurial ecosystem. It provides a basis for studies of other entrepreneurial ecosystems in the CEE region in terms of how they might adapt virtual structures IT-driven digitalisation assumes greater prominence. 


\section{References}

Acs, Z., Stam, E., Audretsch, D., \& O'Connor, A. (2017). The lineages of the entrepreneurial ecosystem approach. Small Business Economics, 49(1), 1-10. https://doi.org/10.1007/s11187-017-98648

Andrews, R. (2010). Organizational social capital, structure and performance. Human Relations, 63(5), 583-608. https://doi.org/10.1177/0018726709342931

Audretsch, D. B., Cunningham, J. A., Kuratko, D. F., Lehmann, E., \& Menter, M. (2019). Entrepreneurial ecosystems: economic, technological, and societal impacts. The Journal of Technology Transfer, 44(2), 313-325. https://doi.org/10.1007/s10961-018-9690-4

Aulet, W. (2013). Disciplined Entrepreneurship : 24 Steps to a Successful Startup, John Wiley and Sons Inc, New York.

Autio, E., Nambisan, S., Thomas, L. D. W., \& Wright, M. (2018). Digital affordances, spatial affordances, and the genesis of entrepreneurial ecosystems. Strategic Entrepreneurship Journal, 12(1), 72 95. https://doi.org/10.1002/sej.1266

Becker, G. S. (1964). Human Capital. Columbia University Press, New York.

Belas, J., Rahman, A., Rahman, M. T., \& Schonfeld, J. (2017). Financial Constraints on Innovative SMEs: Empirical Evidence from the Visegrad Countries. Engineering Economics, 28(5), 552-563.

Bhawe, N., \& Zahra, S. A. (2019). Inducing heterogeneity in local entrepreneurial ecosystems: the role of MNEs, Small Business Economics, 52(2), 437-454. https://doi.org/10.1007/s11187-0179954-7

Békés, G., Kleinert, J., \& Toubal, F. (2006). Spillovers from multinationals to heterogeneous domestic firms: Evidence from Hungary. Discussion Paper No. 2006/16. Budapest: Institute of Economics, Hungarian Academy of Sciences, 32(10), 1408-33. https://doi.org/10.1111/j.14679701.2009.01179.x.

Blank, S., \& Dorf, B. (2012). The Startup Owner's Manual: The Step-by-step Guide for Building a Great Company, K\&S Ranch.

Brajkovic, L. (2018). Human Capital Investment or Academic Marginalism? Understanding the Influence of Political Economy on Higher Education in Post-Socialist Europe, Policy Reviews in Higher Education, 2(2), 151-175.

Brown, R., \& Mawson, S. (2019). Entrepreneurial ecosystems and public policy in action: a critique of the latest industrial policy blockbuster. Cambridge Journal of Regions, Economy and Society, 12(3), 347-368. https://doi.org/10.1093/cjres/rsz011

Cantner, U., Cunningham, J. A., Lehmann, E. E., \& Menter, M. (2020). Entrepreneurial ecosystems: a dynamic lifecycle model. Small Business Economics: An Entrepreneurship Journal, 1-17.

Carvalho, N., \& Yordanova, Z. (2018). Why say no to innovation? Evidence from industrial SMEs in the European Union. Journal of Technology Management \& Innovation,13 (2), 43-56. https://doi.org/10.4067/S0718-27242018000200043

Cavallo, A., Ghezzi, A., \& Balocco, R. (2019). Entrepreneurial ecosystem research: Present debates and future directions. International Entrepreneurship and Management Journal, 15(4), 1291-1321. https://doi.org/10.1007/s11365-018-0526-3 
Corbin, J., \& Strauss, A. (2014). Basics of Qualitative Research: Techniques and Procedures for Developing Grounded Theory. Sage Publications, Thousand Oaks, CA.

Davidsson, P., \& Honig, B. (2003). The role of social and human capital among nascent entrepreneurs. Journal of Business Venturing, 18(3), 301-331.

Dvouletý, O., \& Orel, M. (2020). Determinants of solo and employer entrepreneurship in Visegrád countries: findings from the Czech Republic, Hungary, Poland and Slovakia, Journal of Enterprising Communities: People and Places in the Global Economy, 14 (3), 447-464.

Eisenhardt, K. M. (1989). Building theories from case study research. Academy of Management Review, 14(4), 532-550. https://doi.org/10.5465/AMR.1989.4308385

Engle, A. D., Zaharie, M., Kerekes, K., \& Poór, J. (2020). Who is in Charge Here? Evidence of the Division of Roles and Responsibilities Between Global and Local HR Managers in MNEs Operating in the CEE Region. Journal of East-West Business, 26(1), 81-107. https://doi.org/10.1080/10669868.2019.1689218

Etzkowitz, H. (2003). Innovation in Innovation: The Triple Helix of University-Industry Government Relations. Social Science Information, 42(3), 293-337.

European Commission. (2005). The new SME definition: User guide and model declaration. In European Commission (Eds.), Enterprise and industry publications (p. 14). Brussels. http://ec.europa.eu/enterprise/policies/sme/files/sme_definition/sme_user_guide_en.pdf

Eurostat. (2015). Statistics on small and medium sized enterprises, Eurostat, Brussels, ISSN 2443-8219. http://ec.europa.eu/eurostat/statistics-explained/index.php/Statistics_on_small_and_medium sized_enterprises

Földvári, P., \& van Leeuwen, B. (2005). An Estimation of the Human Capital Stock in Eastern and Central Europe. Eastern European Economics, 43(6), 53-65. https://doi.org/10.2753/EEE00128755430603

Goswami, K., Mitchell, J. R., \& Bhagavatula, S., (2018). Accelerator expertise: Understanding the intermediary role of accelerators in the development of the Bangalore entrepreneurial ecosystem, Strategic Entrepreneurship Journal, March 2018, 12(1), 117-150. https://doi.org/10.1002/sej.1281

Gubik, A. S., \& Farkas, S. (2016). Student Entrepreneurship in Hungary: Selected Results Based on GUESSS Survey. Entrepreneurial Business \& Economics Review, 4(4),123-139.

Guest, G., Bunce, A., \& Johnson, L. (2006). How many interviews are enough? An experiment with data saturation and variability. Field Methods, 18 (1),59-82. https://doi.org/10.1177/1525822X05279903

Hoogendoorn, B., Rud, I., Groot, W., \& Brink, H. (2019). The effects of human capital interventions on entrepreneurial performance in industrialized countries. Journal of Economic Surveys, 33 (3), 798-826. https://doi.org/10.1111/joes.12308.

lenciu, N. M., \& lenciu, I.-A. (2015). Brain drain in Central and Eastern Europe: new insights on the role of public policy. Journal of Southeast European and Black Sea, 15(3), 281-299. https://doi.org/10.1080/14683857.2015.1050799

Invest Europe. (2019). Central and Eastern Europe Private Equity Statistics, 2018. https://www.investeurope.eu/media/2630/ie_cee_report_2018_final.pdf 


\section{DISCUSSION}

Isenberg, D. J. (2011). The entrepreneurship ecosystem strategy as a new paradigm for economic policy: principles for cultivating entrepreneurship. Presentation at the Institute of International and European Affairs, Dublin, 2011.

Johannessen, J.-A. \& Olsen, B. (2010). The future of value creation and innovations: Aspects of a theory of value creation and innovation in a global knowledge economy, International Journal of Information Management, 30(6), 502-511.

Jude, C., \& Silaghi, M. I. P. (2016). Employment effects of foreign direct investment: New evidence from Central and Eastern European countries. International Economics (2110-7017), 145, 32-49. https://doi.org/10.1016/j.inteco.2015.02.003

Jurajda, Š., \& Terrell, K. (2010). Regional unemployment and human capital in transition economies. Economics of Transition, 17(2), 241-274. https://doi.org/10.1111/j.1468-0351.2009.00351.x

Kállay, L., \& Jáki, E. (2019). The impact of state intervention on the Hungarian venture capital market. Economic Research-Ekonomska Istraživanja, 33(1), 1130-1145. https://doi.org/10.1080/1331677X.2019.1629979

Karsai, J. (2018). Government venture capital in Central and Eastern Europe. Venture Capital, 20(1), 73102. https://doi.org/10.1080/13691066.2018.1411040

Kim, P., \& Aldrich, H. (2005). Social capital and entrepreneurship. Foundations and Trends in Entrepreneurship, 1(2), 55-104.

Kornai, J. (2006). The Great Transformation of Central Eastern Europe. Economics of Transition, 14(2), 207-244.

Központi Statisztikai Hivatal (Hungarian Central Statistical Office) (2020). Data on New IT Business Registrations in Budapest, http://statinfo.ksh.hu/Statinfo/themeSelector.jsp?\&lang=en

Kovac, D., Scrbec, N., \& Podobnik, B. (2018). Does it payoff to research economics? - A tale of citation, knowledge and economic growth in transition countries. Physica A, 505, 293-305. https://doi.org/10.1016/j.physa.2018.02.171

Küttim, M., Kallaste, M., \& Venesaar, U. (2014). Entrepreneurship Education at University Level and Students' Entrepreneurial Intentions. Procedia - Social and Behavioral Sciences, 110(24), 658668. https://doi.org/10.1016/j.sbspro.2013.12.910

Leydesdorff, L., \& Deakin, L. (2011). The Triple-Helix Model of Smart Cities: A Neo-Evolutionary Perspective. Journal of Urban Technology, 18(2), 53-63. https://doi.org/10.1080/10630732.2011.601111

Miller, D., \& Acs, Z. (2017). The campus as entrepreneurial ecosystem: The University of Chicago. Small Business Economics, 49 (1), 75-95. https://doi.org/10.1007/s11187-017-9868-4

Morse, J. M., Barrett, M., Mayan, M., Olson, K., \& Spiers, J. (2002). Verification strategies for establishing reliability and validity in qualitative research. International Journal of Qualitative Methods,1(2),13-22. https://doi.org/10.1177/160940690200100202

Nahapiet, J., \& Ghoshal, S. (1998). Social capital, intellectual capital, and the organizational advantage. $\begin{array}{lllll}\text { Academy of } & \text { Management } & \text { Review, } 242-266 .\end{array}$ https://doi.org/10.5465/AMR.1998.533225

Oviatt, B. M., \& McDougall, P. P. (2005). Defining international entrepreneurship and modeling the speed of internationalization. Entrepreneurship Theory and Practice, 29(5),.537-554. https://doi.org/10.1111/j.1540-6520.2005.00097.x 
Ouimet, P., \& Zarutskie, R. (2014). Who works for startups? The relation between firm age, employee age, and growth. Journal of Financial Economics, 112(3), 386-407. https://doi.org/10.1016/j.jfineco.2014.03.003

Pauwels, C., Clarysse, B., Wright, M., \& Van Hove, J. (2016). Understanding a new generation incubation $\begin{array}{llll}\text { model: } \quad \text { The } & \text { accelerator. Technovation, }\end{array}$ https://doi.org/10.1016/j.technovation.2015.09.003

Petersen, A. M., \& Puliga, M. (2017). High-skilled labour mobility in Europe before and after the 2004 enlargement. Journal of the Royal Society Interface, 14(128), 1-13. https://doi.org/10.1098/rsif.2017.0030

Prashantham, S., \& Kumar, K. (2011). How do new ventures in MNC ecosystems proactively overcome interfirm asymmetries? IIMB Management Review (Elsevier Science), 23(3), 177-188. https://doi.org/10.1016/j.iimb.2011.06.001

Prashantham, S., \& Kumar, K. (2019). Engaging with startups: MNC perspectives. IIMB Management Review (Elsevier Science). 31(4), 407-417. https://doi.org/10.1016/j.iimb.2019.01.003

Precup, M. (2017). Venture Capital and Leveraged Buyout: What Is the Difference in Eastern Europe? A Cross-Country Panel Data Analysis. Romanian Journal of European Affairs, 17(2), 30-55.

Radinger-Peer, V., Sedlacek, S., \& Goldstein, H. (2018). The path-dependent evolution of the entrepreneurial ecosystem (EE) - dynamics and region-specific assets of the case of Vienna (Austria). European Planning Studies, 26(8), 1499-1518. https://doi.org/10.1080/09654313.2018.1494136

Radošević, S. (2017). Upgrading technology in Central and Eastern European Economies. IZA World of Labor. 338, 1-11.

Ries, E. (2013). The Lean Startup: How today's entrepreneurs use continuous innovation to create radically successful businesses? Crown Business, New York

Roundy, P. T., \& Bayer, M. A. (2019). To bridge or buffer? A resource dependence theory of nascent entrepreneurial ecosystems, Journal of Entrepreneurship in Emerging Economies, 11(4), 550575. https://doi.org/10.1108/JEEE-06-2018-0064

Sansone, G., Andreotti, P., Colombelli, A., \& Landoni, P. (2020). Are social incubators different from other incubators? Evidence from Italy. Technological Forecasting and Social Change, 158, 120-132. https://doi.org/10.1016/j.techfore.2020.120132

Sansone, G., Ughetto, E., \& Landoni, P. (2021). Entrepreneurial intention: An analysis of the role of Student-Led Entrepreneurial Organizations. Journal of International Entrepreneurship, 1-35. https://doi.org/10.1007/s10843-021-00288-6

Spigel, B., \& Harrison, R. (2018). Toward a process theory of entrepreneurial ecosystems. Strategic Entrepreneurship Journal, 12(1), 151-168. https://doi.org/10.1002/sej.1268

Stam, E. (2015). Entrepreneurial Ecosystems and Regional Policy: A Sympathetic Critique. European Planning Studies, 23(9), 1759-1769. https://doi.org/10.1080/09654313.2015.1061484

Stojčić, N. (2020). Collaborative innovation in emerging innovation systems: Evidence from Central and Eastern Europe. The Journal of Technology Transfer, 1-32. https://doi.org/10.1007/s10961020-09792-8

Sussan, F., \& Acs, Z. J. (2017). The digital entrepreneurial ecosystem. Small Business Economics, 49(1), 55-73. https://doi.org/10.1007/s11187-017-9867-5

Szerb, L., Lafuente, E., Horvath, K., \& Pager, B. (2019). The relevance of quantity and quality entrepreneurship for regional performance: the moderating role of the entrepreneurial 


\section{DISCUSSION}

ecosystem.

Regional

https://doi.org/10.1080/00343404.2018.1510481

Studies,53(9),

$1308-1320$.

Tenca, F., Croce, A., \& Ughetto, E. (2018). Business angels research in entrepreneurial finance: A literature review and a research agenda. Journal of Economic Surveys, 32(5), 1384-1413. https://doi.org/10.1111/joes.12224

Unger, J. M., Rauch, A., Frese, M., \& Rosenbusch, N. (2011). Human capital and entrepreneurial success: a meta-analytic review. Journal of Business Venturing, 26(3), 341-358.

Walsh, K. (2019). Regional capability emergence in an entrepreneurial ecosystem. Journal of Entrepreneurship and Public Policy, 8(3), 359-383. https://doi.org/10.1108/JEPP-04-20190030

Welter, F., \& Smallbone, D. (2011). Institutional Perspectives on Entrepreneurial Behavior in Challenging Environments". Journal of Small Business Management, 49 (1), 107-125. https://doi.org/10.1111/j.1540-627X.2010.00317.x

Wright, M., Siegel, D. S., \& Mustar, P. (2017). An Emerging Ecosystem for Student Start-Ups. Journal of Technology Transfer,42 (4): 909-22. https://doi.org/10.1007/s10961-017-9558-z

Wurth, B., Stam, E., \& Spigel, B. (2021). Toward an entrepreneurial ecosystem research program. Entrepreneurship Theory and Practice, 00 (0), 1-50 https://doi.org/1042258721998948

Yin, R. K. (2017). Case Study Research: Design and Methods. Sage Publications, Thousand Oaks, CA, 6th edition.

Zetzsche, D., \& Preiner, C. (2018). Cross-Border Crowdfunding: Towards a Single Crowdlending and Crowdinvesting Market for Europe. European Business Organization Law Review, 19(2), 217 251. https://doi.org/10.1007/s40804-018-0110-x

The research paper passed the review process. | Received: March 25, 2021; Revised: September 20, 2021; Accepted: October 08, 2021; Pre-published online: December 30, 2021; Published in the regular issue: July 18, 2022. 